\title{
Network of compliance professionals
}

\author{
William G. Greer, BS, CPIA, RLAT, Associate Director, Office for Research \\ Protections, The Pennsylvania State University, University Park, PA
}

\begin{abstract}
Mr. Greer tells Lab Animal how he became involved in research compliance and how compliance professionals are sharing information to meet the challenges they face.
\end{abstract}

\section{How did you first become interested in biomedical research? \\ I spent most of my childhood raising and caring for horses, cattle, sheep and poultry. In addition, I dedicated time to breeding registered dogs-Norwegian Elkhounds and Eskimo Spitz. During that time, I was inspired to become a veterinarian. \\ While enrolled in a pre-veterinary science program, I became interested in immunology and infectious disease research. Eventually my interests switched from providing medical care for individual animals to conducting research that would improve overall animal health.}

\section{You began your career by researching} vaccine development before moving into compliance management. What inspired you to focus on compliance?

After graduation, I accepted a position developing custom vaccines for poultry growers. I had the unique opportunity to visit poultry farms when growers were experiencing increased mortality in their flocks due to infectious diseases. While in the field, I collected tissue and other biological samples, brought them back to the lab, isolated and propagated the problematic pathogen and then developed a vaccine. The vaccines ultimately improved the overall health of poultry flocks, which helped to ensure animal health and the availability of quality sustainable food for human consumption.

While working as a vaccine developer, I was responsible for ensuring that the studies were conducted and the vaccines were developed in accordance with relevant federal standards. I was also responsible for ensuring that federal health and safety regulations were applied and that hazardous materials were handled in accordance with applicable federal regulations.

As the Associate Director for research compliance at The Pennsylvania State University, what do you consider to be the biggest challenges facing compliance professionals?

The traditional response is that compliance professionals need to have and maintain a thorough understanding of federal regulations and policies governing animal care and use programs and ensure they are literally applied. But change is in the air. Researchers are challenging the compliance community to take action to reduce the administrative burden associated with regulatory compliance. Consequently, I believe one challenge facing compliance professionals today is to ensure their organizations' programs remain compliant with federal standards while simultaneously devising methods to apply the standards efficiently and in a manner that minimizes the regulatory burden placed on researchers.

In addition, while regulations are common across the animal care and use spectrum, animal care and use programs are diverse. This diversity is expected and reasonable, considering the different species, procedures and research portfolios among institutions, but has led to variability among programs, which creates an ongoing challenge for IACUC administrators.

\section{You are very active in the IACUC administration community, participating in committees, organizations and meetings. Why is this work important to you?}

In 2005, I instituted IACUC administrators Best Practice Meetings, during which approximately fifty IACUC administrative

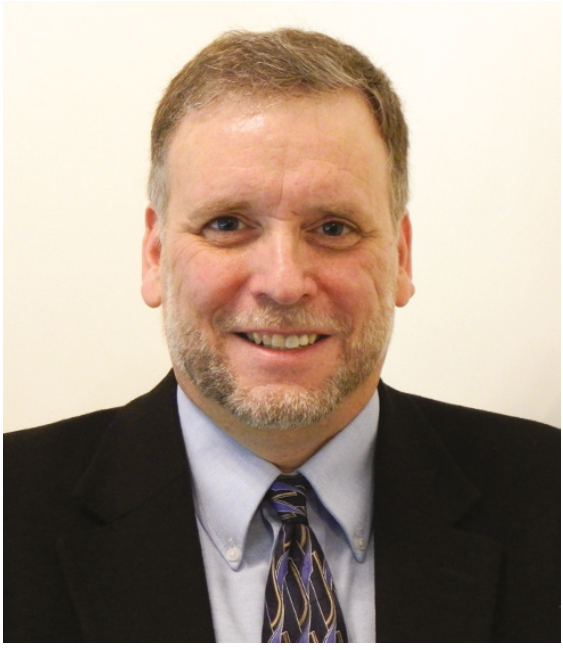

staff members informally discuss common program problems and potential solutions. The meetings are at maximum capacity every year, with many individuals returning year after year, sometimes noting how lessons they learned from prior Best Practice Meetings have improved their programmatic processes.

The number of enthusiastic administrators attending Best Practice Meetings and the overall comments received on program evaluation forms clearly define the importance of providing administrators the opportunity for networking, sharing resources, engaging in peer counseling and providing encouragement. Having the opportunity to play my part by holding annual Best Practice Meetings and facilitating sessions at other training venues is my contribution to maintaining compliant programs that ensure the humane care and treatment of animals.

\section{Is there anything else you'd like to share with Lab Animal readers?}

I have the distinct honor to serve our program accrediting body as an ad hoc consultant to the Association for Assessment and Accreditation of Laboratory Animal Care International counsel on accreditation and to serve as a board member on the Counsel for Certified IACUC Administrators. I also worked with many of my esteemed colleagues to establish the IACUC Administrators Association. I look forward to future opportunities and interactions with my colleagues. 